\title{
Uteroplacental vascular syndromes: Theories, hypotheses and controversies
}

\author{
Roger A McMASTER-FAY* \\ Department of Obstetrics and Gynaecology, Faculty of Medicine, Central Clinical School, University of Sydney, Sydney, New South Wales, Australia
}

\begin{abstract}
The maldevelopment of the spiral arteries in the placental bed reduces uteroplacental blood flow and results in diseases later in the pregnancy. These diseases are here called the uteroplacental vascular syndromes. These syndromes have serious consequence for both the infant and the mother. These pregnancies with a maldeveloped uteroplacental circulation can be detected in the first twenty weeks of pregnancy with uteroplacental Doppler studies. This predictive ability can be improved with addition of maternal biophysical and historical data and biochemical testing of the maternal blood. Prophylactic therapy with aspirin and other antioxidants improves outcomes in some if not all of these syndromes. The potential for these syndromes is probably $15 \%$ to $20 \%$ of nulliparous pregnancies. Further research needs to be done to clarify the above facts and thus better detect these pregnancies and improve interventions and outcomes. The research into the early detection and improving the outcomes of these pregnancies, with otherwise normal mothers and infants, takes a much lower financial profile than the early detection of abnormal foetuses.
\end{abstract}

\section{Introduction}

The maldevelopment of the spiral arteries in the placental bed occurs in up to $15-20 \%$ of nulliparous pregnancies with similar or higher rates in 'high-risk' multiparous pregnancies. The known and probable dynamics (pathophysiology) of how this maldevelopment goes to present as different syndromes, later in the pregnancy, is described. Drug prophylaxis can prevent or delay the clinical onset of these syndromes.

The syndromes are:

Pre-eclampsia (PE) / Eclampsia ('Toxaemia of pregnancy') - in most cases and in many case of Gestation Induced Hypertension (GIH); Preterm delivery (PTD) - in many cases and sometimes in Preterm Rupture of Membranes (PROM); Placental abruption - in many cases, also as antepartum haemorrhage (APH) in some cases; Fetal distress (FD) and Stillbirth (SB) - in many cases. Intrauterine growth restriction (IUGR) depending on the definition - this being the most controversial. The term "Uteroplacental vascular syndromes" (UPVS's) is a one which has been previously been called the 'Great Obstetrical Syndromes' [1], maternal placental syndromes [2], placental syndromes [3] and ischemic placental syndrome [4]. Uteroplacental vascular syndromes better describes the true nature of the pathophysiology of the disease process. We first described most of these syndromes having a common aetiology in an abnormal uteroplacental circulation (UPC) over 25 years ago [5].

The disease of 'toxaemia' of pregnancy (pre-eclampsia and eclampsia) and the other uteroplacental vascular syndromes are still major killers of, otherwise normal, mothers and babies in undeveloped countries of the world [6] but less so anymore in developed countries. Of pregnancies where the spiral arteries fail to undergo normal physiological change, only a quarter $[7,8]$ go on to develop PE. PE occurs in $4.9 \%$ of nulliparous pregnancies [9]. Recently, early (first trimester) maldevelopment of the UPC in combination of chemical and biophysical maternal features has been found to have some clinical utility [10].

\section{Incidences}

Proteinuric hypertension (PE), in developed countries, has a rate of $5 \%$ in nulliparous pregnancies [9] and higher if case of non-proteinuric hypertension with either very high blood pressure or biomarkers such as hyperuricaemia. The rate is higher in 'high-risk' multiparous pregnancies [11]. In an unselected population the rate is $2 \%[7,8]$. South African data just published is dramatically worse [4].

SPTD has a rate of $7 \%$ at $<37$ weeks and $2.5 \%$ at $<33$ weeks in nulliparous pregnancy, with additional cases of PROM [12]. Placental abruption has a rate $0.6 \%$ in nulliparous pregnancy [8] with additional cases of concealed abruption and APH with clinically undiagnosable abruption. FD rate was 3.3\% in an unselected population [7] and a SB rate $1 \%$ of nulliparous pregnancies [9].

IUGR depending on the definition: on weight alone small for gestational age (SGA) below the $10^{\text {th }}$ or $5^{\text {th }}$ centile; asymmetric IUGR Ponderal Index below the $10^{\text {th }}$ or $5^{\text {th }}$ centile. We [13] and others [14] have FD rate is much higher for symmetrical IUGR than for SGA.

\section{Compounding diseases}

Diabetes Type 1: Sibai et al. [15] found that $20 \%$ of patients with insulin-dependent, pregestational diabetes develop PE.

Gestational Diabetes: Bryson et al. [16] that the Odds Ratio of pregnancies complicated with GD developing pregnancy related hypertension was 1.5 compared with the normal's.

*Correspondence to: Roger A McMASTER-FAY, Department of Obstetrics and Gynaecology, Faculty of Medicine, Central Clinical School, University of Sydney, Sydney, New South Wales, Australia, E-mail: roger@rfay.com.au

Key words: placental syndromes, uteroplacental circulation, doppler, aspirin

Received: November 08, 2018; Accepted: November 16, 2018; Published: November 19, 2018 
Obesity: found in nulliparous pregnancies with obesity, the rate of PE was $10.4 \%$ compared with $4.9 \%$ for all nulliparae [9].

Some degree of maldevelopment of the spiral arteries in the placental bed probably occurs in up to $15-20 \%$ of nulliparous pregnancies with similar or higher rates in 'high-risk' multiparous pregnancies [11].

\section{The placental bed: physiology and pathophysiology}

It is 60 years since Geoffrey Dixon and Tom Robertson (later; Ivo Brosens) started publishing their seminal works on the histology of the placental bed in normal and abnormal pregnancies with UPVS's [17]. In normal pregnancy in the placental bed "the spiral arteries after being breeched by the non-villous trophoblast, undergo extensive adaptations and structural alterations in order to provide the intervillous space of the growing placenta with an adequate amount of maternal blood [18]. This process they termed 'physiological change'. Then "from 15 or 16 weeks' gestation, there seems to be a wave of intra-arterial trophoblast migration beyond the deciduo-myometrial junction into the true myometrial segments of the spiral arteries [19].

We were the first described and quantify the development of the normal low resistance circulation with Doppler changes in the UPC in mid-trimester normal nulliparous pregnancy [20]. All the indices of flow in the uterine artery flow velocity waveforms (UAFVW's) showed a continuous fall in resistance from 14 to 24 weeks.

The intimate interrelationship between the spiral arteries and the 'bush-like' placental cotyledons was beautifully described, photographed and illustrated by Wigglesworth almost 50 years ago (Figure 1) [21]. In the abnormal pregnancies with uteroplacental vascular syndromes, this invasion of the trophoblast into the myometrial segment of the spiral arteries fails to occur, the vesicles fail to properly dilate and the normal fall in blood flow resistance to the placenta fails to occur. In the third trimester, in some pregnancies these maldeveloped spiral arteries may further undergo disease changes similar to atherosclerosis. This of atherotic disease process was termed 'acute atherosis' [22], which results in further restriction of blood flow and even complete vascular occlusion causing placental ischemia and infarction (Figure 2).

Ivo Brosens has recently [1] linked the degree of spiral artery disease in the placental bed to the different UPVS, with: PTD, PROM and IUGR having only partial failure of physiological change; PE having absence of physiological change; PE with IUGR, placental abruption and placental infarcts with fetal death, having absence of physiological change with obstructive lesions (acute atherosis). The current two stage

\section{Tensol cast of part of the placenta showing spiral arteries (red) entering the centre of the fetal lobules. (Fetal arteries white)}
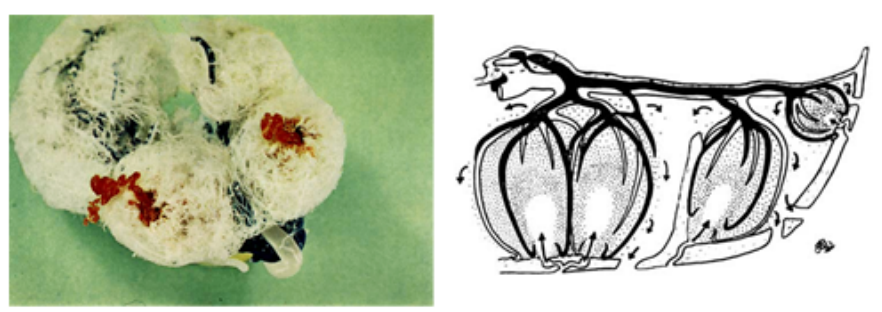

Figure 1. From Wigglesworth [21]

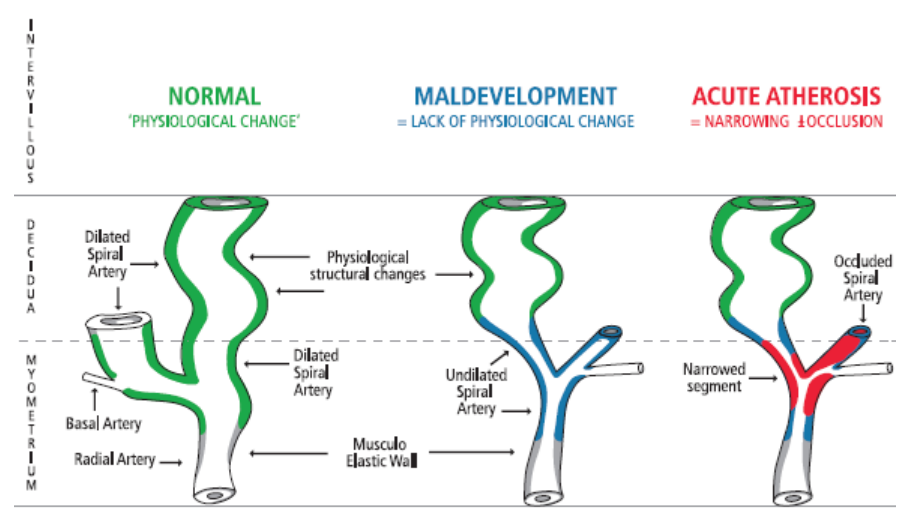

Figure 2. Placental bed spiral artery normal mid-trimester development (of a low resistance circulation - green), maldevelopment (blue) and disease (red)

model for PE of: 1. the vascular stage; 2 . the clinical stage [23]; this staging would also apply to all the UPVS.

\section{UPC doppler studies}

It was just over 35 years when Stuart Campbell strapped to the side of his real-time ultrasound probe a Doppler ultrasound probe [24]. The probe and its device produced not only sound but also a twodimensional flow velocity waveform (FVW). From the uterine artery waveforms, he was able to detect abnormal patterns indicative of higher resistance in the UPC in mid-pregnancy. Almost half in this study had pregnancies with subsequent abnormal outcomes had abnormal midtrimester UAFVW's.

Soon after color Doppler ultrasound machines were developed that allowed it relatively easy to visualise the uterine arteries and produce a UA FVW through the one probe. Subsequently, we [25] and many others were able to confirm Campbell's initial findings and go on to more clearly describe the pathogenesis of the UPVS. But there are at least two features of the UAFVW's in the second trimester that indicate increased resistance: 1. the numerical indices: systolic/diastolic ratio (S/D ratio); Resistance Index (RI); Pulsatility Index; 2 . the early diastolic notch (EDN). Both have clinical utility. I prefer S/D ratio as it is the simplest to understand what is being measured. The EDN has been measured as present or absent and some have attempted to quantitated it [26-29], and we have attempted to computerise it [30].

Combining both the both the indices of flow and the EDN is probably the way forward, as we have attempted [31]. Most have accepted the UAFVW from the side showing the highest resistance gives the most useful information in the second trimester. More research needs to be done to better define abnormality in the UAFVW's in the mid-trimester and we hope to do this with the data from the nuMoM2 study [32].

The degree of "wavy-ness" of the UAFVW equates with its degree of abnormality. In the analysis of the nuMoM2b study data, we will use a Wavyness Index (WI) of:

\section{$\mathrm{WI}=\mathrm{S} / \mathrm{D} \boldsymbol{X}$ notch depth}

WI would then be used to analyse the patterns for the different UPVS.

\section{Biomarkers}

\section{Cell-free fetal DNA (cffDNA)}

CffDNA has been found to be elevated in patients with PE, with the elevation in cffDNA being proportional to the severity of the 
disease [32]. Levine et al. [33] in a prospective series of 120 cases and 120 controls demonstrated that in the 3 weeks before delivery the cffDNA levels in the maternal serum of PE patients rose to more than twice the levels in the controls. They also demonstrated a two-stage elevation of cffDNA in the maternal serum before the onset of PE. The first significant elevation of cffDNA occurred at the end of the second trimester and the second elevation occurred in the last few weeks prior to the development of PE (above). These two peaks in cffDNA are synchronistic with the maldevelopment of the UPC of patients who develop PE, i.e. the failure of physiological change and the development of acute atherosis. We have recently communications as to the role of cffDNA in the pathogenesis of PE [34].

It has been hypothesised that the cffDNA levels rise in the maternal blood, primarily from the syncitotrophoblast. The trophoblast is injured by the narrow (undilated) spiral arteries having a 'jet-hose' effect [35] with associated turbulence.

\section{a-fetoprotein (AFP)}

Raised AFP level was the first bio-marker to be found to be associated with UPVS [36]. The raised AFP has been found to be associated with increased numbers of fetal red blood cells in the maternal blood, thus being caused by leaking of fetal blood into the maternal blood from placental villi. The villous injury being also caused by the 'jet-hose' effect and associated turbulence (above).

\section{Placental Growth Factor (PIGF)}

Lowered PlGF has been studied throughout pregnancy and found to have some clinical utility in all trimesters [10]. The PlGF is associated placental size and so a lower level is an indicator of a smaller functioning placenta due to the reduced UPC.

Combining Doppler and biomarker data into an index of risk of UPVS could look like:

$$
\text { UPVS Index = WI } \boldsymbol{X} \text { AFP (ng/ml) / PlGF (pg/ml) } \boldsymbol{X} 10
$$

\section{Other bio-physical makers}

First trimester uterine artery Doppler studies combined with biophysical and biochemical maternal markers have been shown to predict PE associated with PTD and other UPVS with a modest degree of success [10]. Many attempts have been made to detect other changes in the maternal physiology prior to the clinical manifestation of $\mathrm{PE}$, one of the earliest was ours looking into rising uric acid blood levels and changes in platelet parameters of number and size $[37,38]$. Most other markers of the clinical stage of PE and other UPVS, have been described which can change before the UPVS clinically manifest but they only predate the UPVS by a few weeks at most (eg. sFlt-1 [39])

Last year, the recommendation statement from a US Preventive Services Task Force (USPSTF) on the screening for PE, was: "to measure the blood pressure throughout pregnancy" [40] - nothing more! Thus, the USPSTF was unimpressed all biomarkers, even proteinuria!

\section{Oxidative stress and the two stages of PE}

Why does 'acute atherosis' develop in some spiral arteries with failed 'physiological change' with further serious consequences for mothers and infants and not in others? The two stages of PE with the first vascular phase (above) and the second clinical phase. Redman and Sargent [23] described the change as due to oxidative stress and inflammation but the inflammation could just be a result of the oxidative stress. Roberts and Huble [41] questioned whether oxidative stress were not the link between the two. I hypothesised [35] that the radical oxygen species (ROS) that cause oxidative stress were generated in the maternal liver the enzyme xanthine oxidase - the pathological isoenzyme of xanthine oxidoreductase (XOR) with xanthine dehydrogenase (XDH) non-toxic isoenzyme. The difference is probable genetic and may be nothing more complicated than Mendelian inheritance the gene for activation of XO being recessive and that for $\mathrm{XDH}$ being dominant. I have recently communicated on oxidative stress in PE [42], and proposed that ROS are the toxins of Toxaemia of pregnancy [43].

The oxidative stress versions of the stages of PE are thus:

1. Vascular stage; Intracellular (hepatocyte) oxidative stress;

2. Acute atherosis and clinical disease manifestation stage: were both are caused by intravascular oxidative stress when the ROS are released from the hepatocytes.

\section{Prophylactic therapy}

There is much confusion in this area because of conflicting reports.

\section{Aspirin}

Aspirin is effective at delaying the onset of PE [10] but there is confusion about when the therapy should be started with two metaanalyses recently published in the same edition of American Journal of Obstetrics and Gynecology [44,45], disagreeing as to whether it should be started before 16 weeks gestation or later. All agree about the pathophysiology of a maldeveloped UPC, then if the failure of the normal physiological change that occurs mainly between 14 and 24 weeks gestation, it seems unreasonable to believe the aspirin MUST be started before 16 weeks unless it can be shown that aspirin assists the trophoblast invasion of the spiral arteries by some, as yet undescribed, mechanism and no such evidence exists. Also, those who 'draw a line in the sand' at 16 weeks, have themselves shown that the PE returns after the aspirin therapy is stopped [10]. Clearly the aspirin therapy does not stop the maldevelopment of the uteroplacental circulation and our retrospective study of mid-trimester UA Doppler would confirm this [46].

Many studies, including ours [47] in meta-analysis [48] have shown that aspirin therapy started after 16 weeks delays the onset of / prevents PE. Is low-dosage of aspirin prophylaxis really necessary: Buffered aspirin in $300-325 \mathrm{mg}$ dose (Alka-Seltza ${ }^{\mathrm{R}}$, Bayer, first marketed in 1931) can be taken, one effervescent tablet, twice weekly. As platelet life span is 10 days, at a dose of twice per week only a maximum of only $35 \%$ of platelets would ever be active [49].

\section{Antioxidants}

The original and RCT of vitamins $\mathrm{C}$ and $\mathrm{E}$ in 'high risk' patients [8] showed a benefit in preventing PE where high risk was mainly defined as abnormal early mid-trimester UA Doppler studies. In subsequent studies were not of truly high risk patients as they were selected mainly on past history and biophysical profile. They did not show any benefit from the vitamins thus subsequent meta-analyses did not show any benefit but they were not comparing like with like.

Aspirin as an antioxidant / free radical scavenger: There is nothing in obstetrics literature on aspirin as a free radical scavenger and yet other specialities have published on this topic [50]. The obstetrics literature is mainly interested in aspirins inhibition of prostaglandin synthesis and hence its anti-platelet activity. But anti-platelet activity would mainly be useful in the clinical / 'acute atherosis' stage of the disease and aspirin 
does not appear to an effect on the loss of 'physiological change' in the spiral arteries (above). As Vitamins $\mathrm{C}$ and $\mathrm{E}$ are free radical scavenger, for those who discontinue aspirin prophylaxis at 36 to 37 weeks gestation, it could be replaced by these vitamins.

\section{Conclusions:}

Uteroplacental vascular syndromes is a better description of these syndromes as 'great obstetric syndromes' and placental ischemic syndromes are not specific as placental ischemia only occurs when there is atherosis of the spiral arteries. In UPVS without atherosis there is reduced placental blood flow and also a 'jet hose' effect from the narrowed (undilated) spiral vessels causing placental injury and increased trophoblast shedding with leaking of fetal blood into the maternal circulation.

UPVS are entities which can be predicted in the first half of pregnancy with UA Doppler flow studies. The predictive ability of UA Doppler will almost certainly improve by combining it with the evaluation of chemical markers, such as cffDNA, $\alpha$-fetoprotein and/or PlGF.

Outcomes, of many these otherwise normal pregnancies, can be improved with aspirin and / or antioxidant therapies started before twenty weeks gestation. Assessments of both therapies have been confused by contradictory or inappropriate analysis's, confirming my previous criticism of evidence based medicine [51].

Further research needs to be performed to further clarify the pathogenesis and better prediction as well as prophylaxis / treatment of all these UPVS.

In our current state of prenatal testing there is an imbalance of research funding, where the non-invasive prenatal diagnosis (NIPD) for the detection of abnormal foetuses so they can be aborted, heavily outweighs that spent on the detection and treatment of UPVS with their potential for harming and even killing both the mothers and infants who are otherwise normal.

In conclusion to the Conclusion, is a question I proposed 14 years ago; 'Can evidence based medicine be unscientific? [51]'

\section{References}

1. Brosens I, Pijnenborg R, Vercruysse L, Romero R (2011) The "Great Obstetrical Syndromes" are associated with disorders of deep placentation. Am J Obstet Gynecol 204: 193-201. [Crossref]

2. Ray JG, Vermeulen MJ, Schull MJ, Redelmeier DA (2005) Cardiovascular health after maternal placental syndromes (CHAMPS): population-based retrospective cohort study. Lancet 366: 1797-803. [Crossref]

3. Thilaganathan B (2017) Placental syndromes: getting to the heart of the matter. Ultrasound Obstet Gynecol 49: 7-9.

4. Kwiatkowski S, Kwiatkowska E, Rzepka R, Torbe A, Dolegowska B (2016) Ischemic placental syndrome - prediction and new disease monitoring. J Matern Fetal Neonatal Med 29: 2033-2039. [Crossref]

5. Bewley S, Cooper D, Campbell S (1991) Doppler investigation of uteroplacental blood flow resistance in the second trimester: a screening study for pre-eclampsia and intrauterine growth retardation. Br J Obstet Gynaecol 98: 871-879. [Crossref]

6. Nathan HL, Seed PT, Hezelgrave NL, De Greeff A, Lawley E, et al. (2018) Maternal and perinatal adverse outcomes in women with pre-eclampsia cared for at facility-level in South Africa: a prospective cohort study. J Glob Health 8: 401-411. [Crossref]

7. Bower S, Bewley S, Campbell S (1993) Improved prediction of preeclampsia by twostage screening of uterine arteries using the early diastolic notch and color Doppler imaging. Obstet Gynecol 82: 78-83. [Crossref]

8. Chappell LC, Seed PT, Briley AL, Kelly FJ, Lee R, et al. (1999) Effect of antioxidants on the occurrence of pre-eclampsia in women at increased risk: a randomised trial. Lancet 354: 810-816. [Crossref]
9. Bhattacharya S, Campbell DM, Liston WA, Bhattacharya S (2007) Effect of Body Mass Index on pregnancy outcomes in nulliparous women delivering singleton babies. BMC Public Health 7: 168-76. [Crossref]

10. Rolnik DL, Wright D, Poon LC, O'Gorman N, Syngelaki A, et al. (2017) Aspirin versus Placebo in Pregnancies at High Risk for Preterm Preeclampsia. N Engl J Med 377 613-622. [Crossref]

11. Morris J, Fay RA, Ellwood DA (1998) Abnormal uterine artery waveforms in the second trimester are associated with adverse pregnancy outcome in high risk women. $J$ Matern Fetal Invest 8: 82-84. [Crossref]

12. Kim YM, Chaiworapongsa T, Gomez R, Bujold E, Yoon BH, et al. (2002) Failure of physiologic transformation of the spiral arteries in the placental bed in preterm premature rupture of membranes. Am J Obstet Gynecol 187: 1137-1142. [Crossref]

13. Fay RA, Dey PL, Saadie CM, Buhl JA, Gebski VJ (1991) Ponderal index: a better definition of the 'at risk' group with intrauterine growth problems than birth-weight for gestational age in term infants. Aust N Z J Obstet Gynaeco l31: 17-19. [Crossref]

14. Villar J, de Onis M, Kestler E, Bolaños F, Cerezo R, et al. (1990) The differential neonatal morbidity of the intrauterine growth retardation syndrome. Am J Obstet Gynecol 163: 151-157. [Crossref]

15. Sibai BM, Caritis S, Hauth J, Lindheimer M, VanDorsten JP, et al. (2000) Risks of preeclampsia and adverse neonatal outcomes among women with pregestational diabetes mellitus. Am J Obstet Gynecol 182: 364-369. [Crossref]

16. Bryson CL, Ioannou GN, Rulyak SJ, Critchlow C (2003) Association between gestational diabetes and pregnancy-induced hypertension. Am J Epidemiol 158: 11481153. [Crossref]

17. Dixon HG, Robertson WB (1958) A study of the vessels of the placental bed in normotensive and hypertensive women. J Obstet Gynaecol Br Emp 65: 803-809. [Crossref]

18. Brosens I, Robertson WB, Dixon HG (1967) The physiological response of the vessels of the placental bed to normal pregnancy. J Pathol Bacteriol 93: 569-579. [Crossref]

19. Pijnenborg R, Robertson WB, Brosens I, Dixon G (1981) Review article: trophoblast invasion and the establishment of hemochorial placentation. Placenta 2: 71-92. [Crossref]

20. Fay RA, Ellwood DA, Bruce S, Turner A (1994) Color Doppler imaging of the uteroplacental circulation in the middle trimester: observations on the development of a low resistance circulation. Ultrasound Obstet Gynecol 4: 391-395. [Crossref]

21. Wigglesworth JS (1969) Vascular anatomy of the human placenta and its significance for placental pathology. J Obstet Gynaecol Br Commonw 76: 979-989. [Crossref]

22. Zeek PM, Assali NS (1950) Vascular changes in the decidua associated with eclamptogenic toxemia of pregnancy. Am J Clin Pathol 20: 1099-1109. [Crossref]

23. Redman CWG, Sargent IL (2003) Pre-eclampsia, the placenta and the maternal systemic inflammatory response-A review. Placenta 17: S21-S27. [Crossref]

24. Campbell S, Diaz-Recasens J, Griffin DR, Cohen-Overbeek TE, Pearce JM, et al. (1983) New Doppler technique for assessing uteroplacental blood inflow. Lancet 1 675-677. [Crossref]

25. Fay RA, Ellwood DA, Bruce S, Turner A (1994) Colour Doppler imaging of the uteroplacental circulation in the mid-trimester: features of the uterine artery flow velocity waveform that predict abnormal pregnancy outcome. Aust $N Z \mathrm{~J}$ Obstet Gynaecol 34: 515-519.

26. Bromley B, Frigoletto FD Jr, Harlow BL, Pauker S, Benacerraf BR (1994) The role of Doppler velocimetry in the structurally normal second-trimester fetus with elevated levels of maternal serum alpha-fetoprotein. Ultrasound Obstset Gynecol 4: 377-380. [Crossref]

27. Aardema MW, De Wolf BT, Saro MC, Oosterhof H, Fidler V, et al. (2000) Quantification of the diastolic notch in Doppler ultrasound screening of uterine arteries. Ultrasound Obstet Gynecol 16: 630-634. [Crossref]

28. Park YW, Cho JS, Choi HM, Kim TY, Lee SH, et al. (2000) Clinical significance of early diastolic notch depth: uterine artery Doppler velocimetry in the third trimester. Am J Obstet Gynecol 182: 1204-1209. [Crossref]

29. Parry S, Sciscione A, Haas DM, Grobman WA, Iams JD, et al. (2017) Role of early second-trimester uterine Doppler screening to predict small-for-gestational-age babies in nulliparous women. Am J Obstet Gynecol 217: 594.e1-10.

30. Loupas T, Ellwood DA, Gill RW, Fay RA (1995) Computer analysis of the early diastolic notch in Doppler sonograms of the uterine arteries. Ultrasound Med Biol 21: 1001-1111. [Crossref] 
31. Morris JM, Fay RA, Ellwood DA, Cook CM, Devonald KJ (1996) A randomised controlled trial of aspirin in patients with abnormal uterine artery blood flow. Obste Gynecol 87: 74-78. [Crossref]

32. Lo YM, Leung TN, Tein MS, Sargent IL, Zhang J, et al. (1999) Quantitative abnormalities of fetal DNA in maternal serum in preeclampsia. Clin Chem 45: 184 188. [Crossref]

33. Levine RJ, Qian C, Leshane ES, Yu KF, England LJ, et al. (2004) Two-stage elevation of cell-free fetal DNA in maternal sera before onset of preeclampsia. Am J Obstet Gynecol 190: 707-713. [Crossref]

34. McMaster-Fay RA, Hyett JA (2016) Cell-free fetal DNA in the pathogenesis of preeclampsia. Am J Obstet Gynecol 214: 548. [Crossref]

35. McMaster-Fay RA (2008) Pre-eclampsia: a disease of oxidative stress resulting from the catabolism of DNA (primarily fetal) to uric acid by xanthine oxidase in the maternal liver; an hypothesis. Biosci Hypotheses 1: 35-43.

36. Konchak PS, Bernstein IM, Capeless EL (1995) Uterine artery Doppler velocimetry in the detection adverse obstetric outcomes in women with unexplained elevated serum a-fetoprotein levels. Am J Obstet Gynecol 173: 1115-1119. [Crossref]

37. Liao S, Vickers MH, Stanley JL, Baker PN, Perry JK (2018) Human Placental Growth Hormone Variant in Pathological Pregnancies. Endocrinol 159: 2186-2198. [Crossref]

38. Fay RA, Bromham DR, Brooks JA, Gebski VJ (1985) Platelets and uric acid in the prediction of preeclampsia. Am J Obstet Gynecol 152: 1038-1039. [Crossref]

39. Herraiz I, Quezada MS, Rodriguez-Calvo J, Gómez-Montes E, Villalaín C, et al. (2018) Longitudinal change of sFlt-1/PlGF ratio in singleton pregnancy with early-onset fetal growth restriction. Ultrasound Obstet Gynecol 52: 613-618. [Crossref]

40. USPSTF (2017) Screening for Preeclampsia US Preventive Services Task Force Recommendation Statement. JAMA 317: 1661-1667. [Crossref]

41. Roberts JM, Hubel CA (1999) Is oxidative stress the link in the two-stage model of pre-eclampsia? Lancet 354: 788-789. [Crossref]
42. McMaster-Fay RA (2017) Oxidative stress and inflammatory biomarkers in normal and preeclamptic pregnancies. Am J Obstet Gynecol 217: 492-493. [Crossref]

43. McMaster-Fay RA (2017) Free Oxygen Radicals: The Toxins of Preeclamptic and Eclamptic Toxaemia of Pregnancy. Ann Clin Exp Hypertension 5: 1052-1055.

44. Roberge S, Nicolaides K, Demers S, Hyett J, Chaillet N, et al. (2017) The role of aspirin dose on the prevention of preeclampsia and fetal growth restriction: systematic review and meta-analysis. Am J Obstet Gynecol 216: 110-120. [Crossref]

45. Meher S, Duley L, Hunter K, Askie L (2017) Antiplatelet therapy before or after 16 weeks' gestation for preventing preeclampsia: an individual participant data metaanalysis. Am J Obstet Gynecol 216: 121-128. [Crossref]

46. Leduc F, Park F, McMaster-Fay R, Hyett J (2015) Does low dose aspirin effect mean uterine artery Doppler pulsatility index in women deemed high risk for early preeclampsia? Ultrasound Obstet Gynecol 46(Suppl. 1): 210-211.

47. Morris JM, Fay RA, Ellwood DA, Cook CM, Devonald KJ (1996) A randomised controlled trial of aspirin in patients with abnormal uterine artery blood flow. Obstet Gynecol 87: 74-78. [Crossref]

48. Chien PF, Arnott N, Gordon A, Owen P, Khan KS (2000) How useful is uterine artery Doppler flow velocimetry in the prediction of pre-eclampsia, intrauterine growth retardation and perinatal death? An overview. BJOG 107: 196-208. [Crossref]

49. Kuhn W, Müller T, Bttner T, Gerlach M (1995) Aspirin as a free radical scavenger: consequences for therapy of cerebrovascular ischemia. Stroke 26: 1959-6033. [Crossref]

50. Fay RA, Hughes AO, Farron NT (1983) Platelets in pregnancy: hyperdestruction in pregnancy. Obstet Gynecol 61: 238-240. [Crossref]

51. McMaster-Fay R (2004) Can evidence-based medicine be unscientific? Aust N Z J Obstet Gynaecol 44: 173-174. [Crossref]

Copyright: (C2018 McMASTER-FAY RA. This is an open-access article distributed under the terms of the Creative Commons Attribution License, which permits unrestricted use, distribution, and reproduction in any medium, provided the original author and source are credited. 